\title{
Epigallocatechin-3-gallate improves nonalcoholic steatohepatitis model mice expressing nuclear sterol regulatory element binding protein-1c in adipose tissue
}

\author{
TAKATO UENO ${ }^{1}$, TAKUJI TORIMURA $^{2}$, TORU NAKAMURA ${ }^{2}$, RAMADOSS SIVAKUMAR $^{1}$, \\ HITOMI NAKAYAMA ${ }^{3}$, SYUICHI OTABE ${ }^{3}$, XIAOHONG YUAN $^{3}$, KENTARO YAMADA $^{3}$, \\ OSAMU HASHIMOTO ${ }^{2}$, KINYA INOUE ${ }^{2}$, HIRONORI KOGA ${ }^{2}$ and MICHIO SATA ${ }^{2}$ \\ ${ }^{1}$ Research Center for Innovative Cancer Therapy, Kurume University, Kurume, Japan; Divisions of ${ }^{2}$ Gastroenterology; \\ ${ }^{3}$ Endocrinology and Metabolism, Department of Medicine, Kurume University School of Medicine, Kurume, Japan
}

Received February 5, 2009; Accepted April 2, 2009

DOI: 10.3892/ijmm_00000200

\begin{abstract}
We examined whether or not epigallocatechin-3gallate (EGCG) improves liver injury of nonalcoholic steatohepatitis (NASH) model mice expressing nuclear sterol regulatory element-binding protein 1c (nSREBP-1c) in adipose tissue. nSREBP-1c transgenic C57BL6 mice aged 30 weeks were divided into group 1 (no treatment), group 2 (ascorbic acid alone), group 3 (ascorbic acid and $0.05 \%$ EGCG), and group 4 (ascorbic acid and $0.1 \%$ EGCG). At 42 weeks, we performed measurement of liver weight to body weight, biochemical assays, morphometry of liver specimens, immunohistochemistry for 8-hydro-2'-deoxyguanosine (8-OhdG), and Western blotting for insulin and TNF- $\alpha$ signalings. Ratio of liver weight to body weight in the high dose EGCG-treated group (group 4) was significantly lower than those of groups 1 and $2(\mathrm{p}<0.05$ and $<0.01$, respectively). Blood ALT, glucose, total cholesterol, and triglyceride levels of group 4 were significantly low compared with those of the EGCGnon-treated group (groups 1 and 2) ( $<<0.05$, respectively). The degrees of steatosis, inflammation, ballooning hepatocytes and Mallory-Denk bodies in group 4 significantly improved
\end{abstract}

Correspondence to: Dr Takato Ueno, Research Center for Innovative Cancer Therapy, Kurume University, 67 Asahi-machi, Kurume, 830-0011, Japan

E-mail: takato@med.kurume-u.ac.jp

Abbreviations: epigallocatechin-3-gallate, EGCG; nonalcoholic steatohepatitis, NASH; nuclear sterol regulatory element-binding protein 1c, nSREBP-1c; 8-hydro-2'-deoxyguanosine, 8-OhdG; insulin receptor substrate-1, IRS-1; phosphorylated IRS-1, pIRS-1; nonalcoholic fatty liver disease, NAFLD; nonalcoholic steatohepatitis, NASH; aspartate aminotransferase, AST; alanine aminotransferase, ALT; glycogen synthase kinase, GSK; hepatic stellate cells, HSC

Key words: nonalcoholic fatty liver disease, nonalcoholic steatohepatitis, nuclear sterol regulatory element-binding protein $1 \mathrm{c}$, green tea polyphenol compared with those in other groups ( $\mathrm{p}<0.05$, respectively). The 8-OhdG immunolocalization in liver tissues of the group 4 obviously decreased compared with those of groups 2 and 3 . For Western blotting, the expressions of insulin receptor substrate-1 (IRS-1) and phosphorylated IRS-1 (pIRS-1) in liver tissues of group 4 increased compared with those of groups 2 and 3. On the other hand, the expressions of pAkt, pIKK $\beta$ and $\mathrm{pNF}-\kappa \mathrm{B}$ decreased compared with those of groups 2 and 3. From these results, EGCG reduces inflammation, insulin resistance and oxidative stress, and suppresses liver injury in nSREBP-1c transgenic mice.

\section{Introduction}

Although the obesity epidemic is a worldwide phenomenon, the severity of the epidemic differs greatly from region to region. The prevalence of obesity among Japanese adults is $3.4 \%$ in males and $3.8 \%$ in females, and is around one tenth of that in the USA (1). In addition, currently in Japan almost $30 \%$ of adult males and females over 50 years old are obese. This rising incidence of obesity parallels the dramatic increase in fatty liver in these age groups. Based on annual health checks, the prevalence of fatty liver diagnosed by ultrasonography increased from $10 \%$ in 1980 to $20-40 \%$ in 2000 among adults. Thus, nonalcoholic fatty liver disease (NAFLD) is now emerging as the most common liver disease in Japan $(2,3)$. The recent worldwide rise in the number of patients with nonalcoholic steatohepatitis (NASH) tends to parallel the increase in metabolic syndrome, which includes obesity, type 2 diabetes and hyperlipidemia (4).

NAFLD mainly comprises of simple steatosis that is considered benign, however some patients have nonalcoholic steatohepatitis (NASH), which is a clinicopathological entity characterized by the development of hepatic histological changes resembling those induced by excessive alcohol intake that occur in the absence of alcohol abuse (5). Some patients with NASH progress to end-stage liver disease, such as cirrhosis and hepatocellular carcinoma in as little as a decade, and treatment of NASH is therefore very important. However, no single agent improves the histological end points and long-term outcomes (6-8). 
Lipodystrophic mice expressing nuclear sterol regulatory element-binding protein 1c (nSREBP-1c) in the adipose tissues show severe insulin resistance, and develop NASH. These animals have marked fatty liver accompanied by hyperlipidemia, hypoleptinemia, and hypoadiponectinemia (9). Immunoreactive 8-hydroxy-2'-deoxyguanosine was observed in the livers of these model mice, suggesting that in addition to insulin resistance, oxidative stress is involved in the development of the NASH-like lesions.

On the other hand, epigallocatechin-3-gallate (EGCG), a type of green tea polyphenol, is a major component of green tea extract, and has the effects of body-fat reduction (10) and antihyperlipidemia $(11,12)$. Therefore, EGCG is useful for NASH patients with obesity and/or hyperlipidemia, but there are no reports indicating that EGCG shows improvement of NASH. In the present study, we examined whether or not catechins improve liver injury of NASH model mice expressing nSREBP-1c in adipose tissue.

\section{Materials and methods}

Animals and treatment. The experimental protocol was approved by the Ethics Review Committee for Animal Experimentation of Kurume University School of Medicine. Transgenic C57BL6 mice (Jackson Lab, ME) expressing nSREBP-1c in adipose tissue were purchased from The Jackson Laboratory (Bar Harbor, ME) (13). We identified nSREBP-1c transgenic mice by amplifying genomic DNA isolated from tails by polymerase chain reaction using a forward primer 5'-CTACATTCGCTTTCTGCAAC-3', and used heterozygous transgenic mice in the following studies. They were bred in our laboratory, mating with wild-type C57BL6 mice (Jackson Lab), in plastic cages with wood chip bedding at a temperature of $18-22^{\circ} \mathrm{C}$, moisture of $40-60 \%$, and on a 12-h light/dark cycle. They were supplied with regular mouse chow (1450 kj/100 g, protein; $24.9 \mathrm{~g} / 100 \mathrm{~g}$, fat; $4.6 \mathrm{~g} / 100 \mathrm{~g}$, Nippon CLEA; Shizuoka, Japan) and water ad libitum. nSREBP-1c transgenic C57BL6 male mice aged 30 weeks, which show the typical NASH in liver histology at this age (9), were prepared and used in this study. These mice were divided into four groups [group 1, mice given distilled water alone $(n=6)$; group 2 , mice given distilled water containing $0.005 \%$ ascorbic acid, which is used to block the oxidation of EGCG ( $\mathrm{n}=6)$; group 3, mice given distilled water containing $0.005 \%$ ascorbic acid and low dose EGCG (0.05\%) $(\mathrm{n}=6)$; group 4 , mice given distilled water containing $0.005 \%$ ascorbic acid and high dose EGCG $(0.1 \%)(n=6)]$, and body weight was measured weekly for 12 weeks. After mice were anethetized with ether at week 43 , body weight was measured, blood sample was collected from inferior vena cava, and these mice were examined as follows.

Measurement of body weight and liver weight at week 43. The body and liver weights of mice in each group after sacrifice were recorded and the percentage of expression of liver weight to body weight was measured.

Biochemical assays containing serum biological markers. Aspartate aminotransferase (AST), alanine aminotransferase (ALT), glucose, total cholesterol, triglyceride, phospholipid

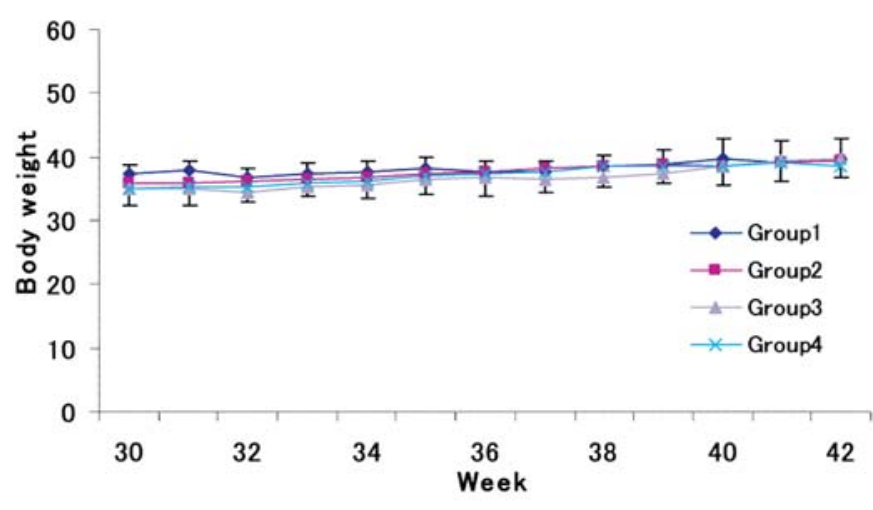

Figure 1. Changes of body weight in mice in the four groups. Body weight of mice in the four groups gradually increased throughout the course of the experiment period, but there is no significant difference among each group.

Table I. Ratio of liver weight to body weight and blood biochemical assay.

\begin{tabular}{lcccc}
\hline Group & 1 & 2 & 3 & 4 \\
\hline $\begin{array}{l}\text { Liver weight/ } \\
\text { body weight }\end{array}$ & $12.8 \pm 2^{\mathrm{a}}$ & $15.2 \pm 1.8^{\mathrm{b}}$ & $12.4 \pm 5.6$ & $7.2 \pm 4.8$ \\
x100 (\%) & & & & \\
AST & $200 \pm 132$ & $183 \pm 8$ & $248 \pm 153$ & $187 \pm 57$ \\
ALT & $321 \pm 260^{\mathrm{a}}$ & $309 \pm 47^{\mathrm{a}}$ & $286 \pm 257$ & $151 \pm 67$ \\
Glucose & $230 \pm 35$ & $274 \pm 23$ & $272 \pm 45$ & $315 \pm 54$ \\
Triglyceride & $50 \pm 23^{\mathrm{a}}$ & $56 \pm 19^{\mathrm{a}}$ & $35 \pm 25$ & $30 \pm 7$ \\
Total cholesterol & $156 \pm 26^{\mathrm{a}}$ & $176 \pm 17^{\mathrm{a}}$ & $132 \pm 54$ & $107 \pm 42$ \\
Free fatty acid & $508 \pm 171$ & $498 \pm 68$ & $466 \pm 116$ & $496 \pm 126$ \\
Phospholipid & $288 \pm 47^{\mathrm{a}}$ & $309 \pm 41^{\mathrm{a}}$ & $240 \pm 101$ & $199 \pm 57$ \\
\hline
\end{tabular}

Group 1, mice given distilled water alone $(n=6)$; group 2, mice given distilled water containing $0.005 \%$ ascorbic acid alone $(n=6)$; group 3 , mice given distilled water containing $0.005 \%$ ascorbic acid and low dose EGCG $(0.05 \%)$ $(n=6)$; group 4 , mice given distilled water containing $0.005 \%$ ascorbic acid and high dose EGCG $(0.1 \%)(n=6)$. EGCG, epigallocatechin-3-gallate; ${ }^{a} \mathrm{p}<0.05$, ${ }^{\mathrm{b}} \mathrm{p}<0.01$ compared with group 4 .

and free fatty acid levels were measured according to the manufacturer's instructions.

Histological diagnosis and morphometry of liver specimens. Paraffin-embedded sections of the liver were stained with either hematoxylin-eosin for standard microscopy and AzanMallory stain to observe the localization of extracellular matrix. The specimens were reviewed by two independent pathologists. Each specimen was assigned to one of the following histological subgroups for the purpose of comparative analysis, type 1 , simple steatosis affecting $>33 \%$ of the lobules; type 2 , steatosis and lobular inflammation; type 3 , steatosis and ballooning; type 4, steatosis, ballooning hepatocytes and Mallory-Denk bodies or fibrosis. We dealt with types 3 and 4 as NASH, as described previously (14). In addition, we performed morphometry of liver specimens using the histological scoring system of Kleiner et al (15). 

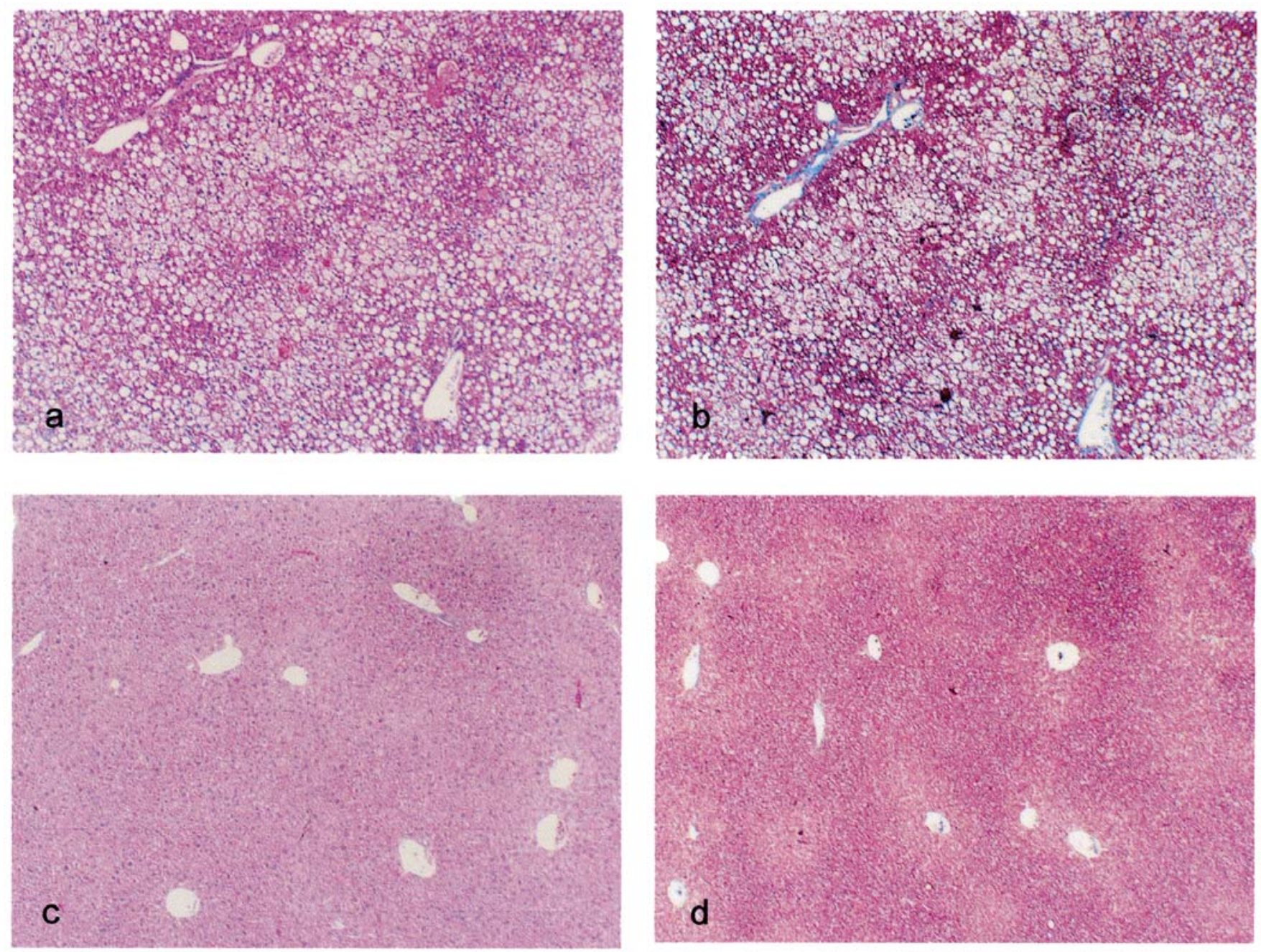

Figure 2. Histological futures of liver specimens. (a) Mouse treated with $0.005 \%$ ascorbic acid for 12 weeks. Hematoxylin-eosin stain, x100. (b) Mouse treated with $0.005 \%$ ascorbic acid for 12 weeks; Azan-Mallory stain, x100. (c) Mouse treated with $0.005 \%$ ascorbic acid and $0.1 \%$ EGCG for 12 weeks; Hematoxylineosin stain, x100. (d) Mouse treated with $0.005 \%$ ascorbic acid and 0.1\% EGCG for 12 weeks; Azan-Mallory stain, x100. Immunoreactive products for anti8-OhdG antibody localized in the cytoplasm of hepatocytes, especially deformed hepatocytes with fat droplets. Liver tissues of mice treated with $0.005 \%$ ascorbic acid for 12 weeks show histological features of typical NASH. However, those of mice with $0.005 \%$ ascorbic acid and $0.1 \%$ EGCG are similar to normal liver.

Immunohistochemistry. Immunoreactive products of 8-hydro2'-deoxyguanosine (8-OhdG), a marker of oxidative DNA damage, in the liver were examined. Paraffin sections were incubated overnight with mouse monoclonal anti-8-OhgG antibody (Japan Institute for the Control of Aging, Fukuroi, Japan), followed by incubation with alkaline phosphataselabeled horse antimouse $\mathrm{IgG}$ (Vector, Burlingame, CA) and visualization by diamnobenzidine. The degree of $8-\mathrm{OhdG}$ immunolocalization in the liver tissues was categorized as 0 , 1,2 or 3 . That is, 0 , none in liver tissue; $1,<1 / 3$ in the intrahepatic lobules; $2,1 / 3-2 / 3$ in the intrahepatic lobules; and 3 , $>2 / 3$ in the intrahepatic lobules.

Western blotting. Western blotting was performed using antiinsulin receptor (IR), anti-insulin receptor substrate (IRS)-1 and anti-phosphorylated IRS-1 (pIRS-1), anti-pGSK $3 \alpha / \beta$ antibodies for insulin signaling, and using anti-Akt, -pAkt, $-\mathrm{I} \kappa \mathrm{B} \alpha,-\mathrm{pI} \kappa \mathrm{B} \alpha,-\mathrm{NF}-\kappa \mathrm{B}$ and $-\mathrm{pNF}-\kappa \mathrm{B}$ antibodies for TNF- $\alpha$ signaling in liver tissues. Whole extracts were prepared from liver tissues using Triton lysis buffer-containing protease and phosphatase inhibitors. Protein concentration of the extracts was determined, and $40 \mu \mathrm{g}$ of protein was electrophorased on $10 \%$ SDS-polyacrylamide gels. The gels were then blotted onto the nitrocellulose membrane.

Statistical analysis. Numerical data were expressed as means \pm SD. Student's t test was performed to assess statistical significance among each group. P-values $<0.05$ were considered significant.

\section{Results}

Changes of body weight of mice in the four groups. Body weight of mice in the four groups gradually increased throughout the course of the experiment period as shown in Fig. 1, but there was no significant difference among each group. 

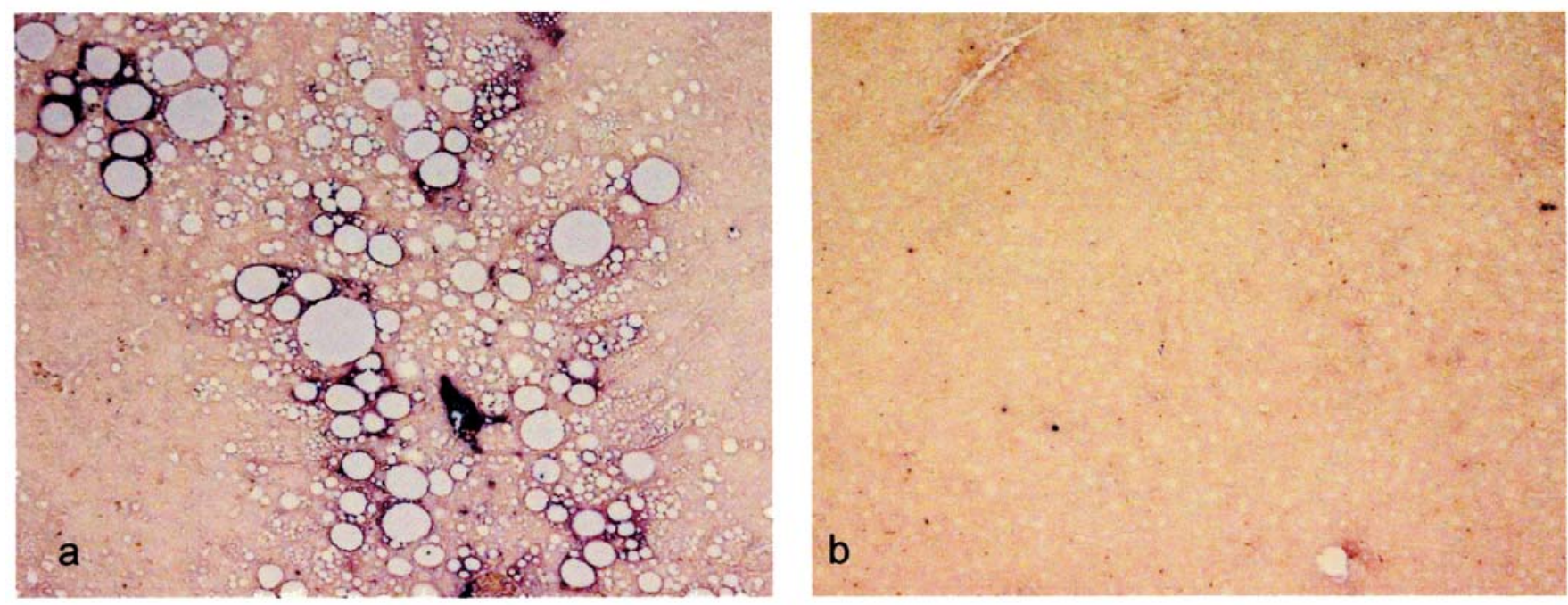

Figure 3. 8-OhdG immunolocalization in liver tissues. (a) 8-OhdG immunolocalization in the liver tissues of the $0.005 \%$ ascorbic acid-treated group is at grade 3 , x 100 . (b) 8 -OhdG immunolocalization in the liver tissues of the $0.005 \%$ ascorbic acid and $0.1 \%$ EGCG-treated group is at grade 1 , $\mathrm{x} 100$. The degree of 8 -OhdG immunolocalization in the liver tissues of the $0.005 \%$ ascorbic acid and $0.1 \%$ EGCG-treated group is low compared with that of other groups.

Ratio of liver weight to body weight at week 43. Ratio (percentage of expression) of liver weight to body weight in the high dose EGCG-treated group (group 4) was lowest compared with that of other groups (group 1, 12.8 \pm 2 ; group 2, 15.2 \pm 1.8 ; group 3, 12.4 \pm 5.6 ; and group 4, 7.2 \pm 4.8 ), and the difference between group 4 and groups 1 and 2 was significant $(\mathrm{p}<0.05$ and $<0.01$, respectively) (Table I).

Biochemical assays containing serum biological markers. Blood ALT, total cholesterol, triglyceride and phospholipid levels of group 4 were significantly low compared with those of groups 1 and 2 ( $<<0.05$, respectively) (Table I). The elevation of serum ALT, AST levels by EGCG treatment was not recognized. In addition, there were no significant differences between AST, free fatty acid, and glucose levels between any of the groups.

Morphometry of liver specimens. The degrees of steatosis, intralobular fibrosis, ballooning hepatocyte appearance and Mallory-Denk body appearance in group 4 significantly decreased compared with those in other groups $(\mathrm{p}<0.05)$ (Table II, Fig. 2).

Immunohistochemistry. Immunoreactive products for anti8-OhdG antibody localized in the cytoplasm of hepatocytes, especially deformed hepatocytes with fat droplets (Fig. 3). The 8-OhdG immunolocalization in liver tissues of group 4 showed an obvious decrease compared with those of other groups, and the difference between the degree of $8-\mathrm{OhdG}$ immunolocalization in group 4 and that of groups 2 and 3 was significant $(\mathrm{p}<0.05)$ (Table II, Fig. 3).

Western blotting. In Western blotting, the expressions of IR and pIRS-1 in liver tissues of group 4 increased compared with those of other groups. On the other hand, the expressions of pAkt, pIKKß and pNF-kB in liver tissues of group 4 decreased compared with those of other groups (Fig. 4).
Table II. Morphometry of liver tissues and degree of 8-OhdG immunolocalization in each group.

\begin{tabular}{lllll}
\hline Group & \multicolumn{1}{c}{1} & \multicolumn{2}{c}{3} & 4 \\
\hline Steatosis & $2.9 \pm 0.4^{\mathrm{a}}$ & $3.0 \pm 0^{\mathrm{a}}$ & $2.4 \pm 0.5^{\mathrm{a}}$ & $1.0 \pm 1.0$ \\
Ballooning hepatocyte & $1.3 \pm 0.5^{\mathrm{a}}$ & $2.0 \pm 0^{\mathrm{a}}$ & $1.0 \pm 0^{\mathrm{a}}$ & $0.4 \pm 0.5$ \\
Mallory-Denk body & $0.9 \pm 0.4^{\mathrm{a}}$ & $1.8 \pm 0.4^{\mathrm{a}}$ & $0.8 \pm 0.4^{\mathrm{a}}$ & $0.4 \pm 0.5$ \\
Fibrosis & $1.3 \pm 0.8$ & $1.0 \pm 0.7$ & $1.2 \pm 0.4$ & $0.8 \pm 1.1$ \\
8-OhdG localization & $1.4 \pm 0.5$ & $2.2 \pm 1.1^{\mathrm{a}}$ & $1.8 \pm 1.3^{\mathrm{a}}$ & $1.2 \pm 0.4$ \\
\hline
\end{tabular}

Group 1, mice given distilled water alone $(\mathrm{n}=6)$; group 2, mice given distilled water containing $0.005 \%$ ascorbic acid alone $(\mathrm{n}=6)$; group 3, mice given distilled water containing $0.005 \%$ ascorbic acid and low dose EGCG $(0.05 \%)(n=6)$; group 4 , mice given distilled water containing $0.005 \%$ ascorbic acid and high dose EGCG $(0.1 \%)(\mathrm{n}=6)$. EGCG, epigallocatechin3-gallate: ${ }^{\mathrm{a}} \mathrm{p}<0.05$ compared with group 4 .

\section{Discussion}

Nonalcoholic fatty liver disease (NAFLD) is associated with metabolic syndrome. The metabolic syndrome is characterized by insulin resistance, which is produced by a complex interaction between genetic factors, macronutrient intake and lifestyle that alters the cytokine profile, cell biology and biochemical milieu of the liver, adipose tissue and striated muscle. The resultant disequilibrium in lipid homeostasis causes triglycerides to accumulate in the liver (16). An increase in oxidative stress, due to the generation of reactive oxygen species as a result of mitochondrial abnormalities and induction of the cytochrome P-450 system is one mechanism by which the nonalcoholic fatty liver develops into NASH (4). The pathogenesis of cytologic ballooning and Mallory-Denk body formation and their role in NAFLD remain to be defined. In addition, inflammation and fibrosis are likely to be secondary to cirrhosis, hepatocellular carcinoma and death $(2,3,17)$. 
a

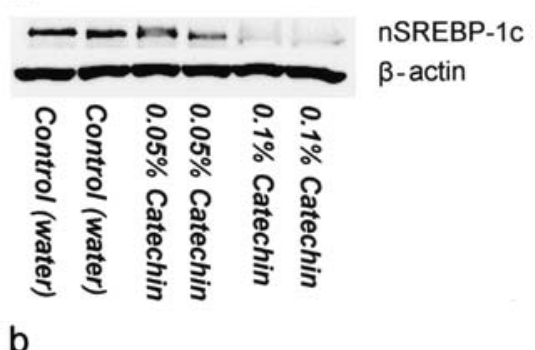

b

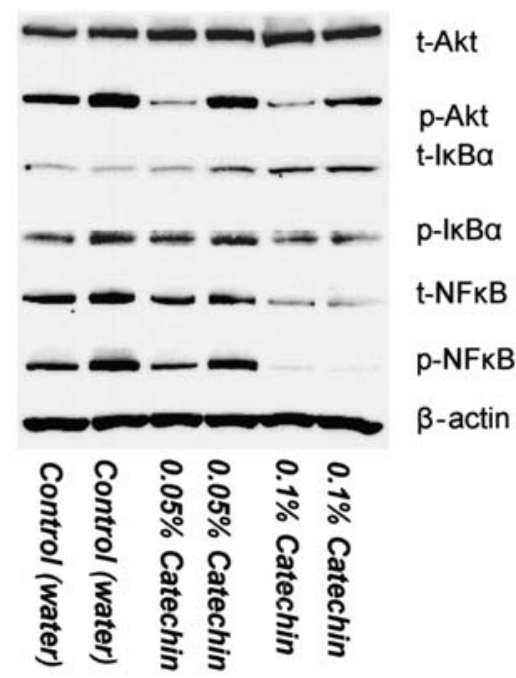

C

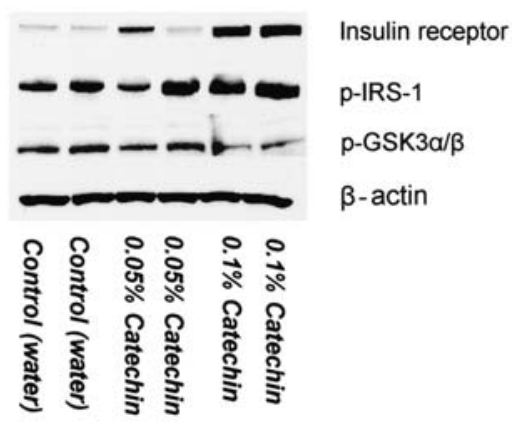

Figure 4. Western blotting. IкB, Inhibitor of $\kappa B$; NF-кB: nuclear factor $\kappa B$; $\mathrm{t}$, total; p, phospholylated; IRS, insulin receptor substrate; GSK, glycogen synthase kinase. For Western blotting, the expressions of IR and pIRS-1 in liver tissues of group 4 increased compared with those of other groups. On the other hand, the expressions of pAkt, pIKKß and pNF- $\mathrm{KB}$ in group 4 decrease compared with those of other groups.

EGCG is an antioxidant and chemopreventional polyphenol that is found in green tea. It blocks activation of Ap-1 or $\mathrm{NF}-\kappa \mathrm{B}$ (18). EGCG has shown the inhibition of activation of IKK $\alpha$, phosphorylation and subsequent degradation of IкB $\alpha$ (18). In addition, EGCG suppresses the proliferation of hepatic stellate cells and production of extracellular matrix in the hepatic fibrosis (19-21). Yumei et al reported that EGCG induced the de novo synthesis of glutathione and antifibrogenic effects in passaged rat hepatic stellate cells $(22,23)$.

In the present study, green tea polyphenols containing EGCG showed effects of reducing inflammation, insulin resistance and oxidative stress (24-26), and improved the liver injury of transgenic mice expressing nSREBP-1c in the adipose tissue. EGCG inhibits nSREBP-1c expression in adipose tissues and Akt, IкB $\alpha$ and NF-кB expressions of liver tissues, and improves the insulin resistance of the liver tissues by promoting the functional recovery of the insulin receptor, insulin receptor substrate-1 (IRS-1) and glycogen synthase kinase (GSK) in the nSREBP-1c transgenic NASH model mice. The direct effect of EGCG to this model mouse is unclear. Its mechanism is likely due to the antioxidant and chemoprevention effects of EGCG (18).

Ingestion of tea rich catechins leads to a reduction in body fat and malondialdehyde-modified LDL in men (27). In obese individuals, body fat mainly accumulates in submucosal and visceral adipose tissue. Obesity alters both the cellular composition and function of adipose tissue. Adipose tissue of obese individuals contains an increased number of macrophages. Macrophages, adipocytes, and other cellular components of adipose tissue produce numerous circulating inflammatory markers including pro- and anti-inflammatory factors, chemokines, growth factors, and proteases that include a systemic inflammatory state and insulin resistance seen in individuals with increased body mass index (28). In this study, there is no significant difference among the four groups for body weight. Probably, the visceral adipose tissue of nSREBP-1c transgenic mice is less than that of wild type C57BL6 mice, and the significant difference is not recognized among each group.

The liver component of this metabolic disorder is NAFLD, which includes a spectrum of liver pathology ranging from steatosis to cirrhosis. Steatosis is often seen in obese individuals, and both presence and severity of steatosis correlate positively with adiposity. Increased hepatic free fatty acid oxidation that occurs in steatotic livers increases the generation of reactive oxygen species. Increased hepatocyte exposure to reactive oxygen species generates a state of oxidant stress and mitochondrial dysfunction, including hepatocellular injury and activation of hepatic stellate cells (HSC). In NAFLD, intestine-originated endotoxin accumulates the substance in the liver rather than to escape from liver. Increased levels of glucose and insulin up-regulate the synthesis of transforming growth factor- $\beta$, angiotensin II, leptin, adiponectin and so on by HSC (29-31), and develop to the hepatic fibrosis.

In this study, there was no evidence of side effects by EGCG treatment. It will be important to clearly determine whether EGCG or green tea consumption can be used as a tool to prevent the development of NASH.

\section{Acknowledgements}

This research was supported by a Grant-in-Aid from the University and Society Collaboration and from COE Research from the Ministry of Education, Culture, Sports, Science and Technology of Japan.

\section{References}

1. Yoshiike $\mathrm{N}$ and Lwin $\mathrm{H}$ : Epidemiological aspects of obesity and NASH/NAFLD in Japan. Hepatol Res 33: 77-82, 2005.

2. Hashimoto E, Yatsuji S, Kaneda H, Yoshioka Y, Taniai M, Tokushige K and Shiratori K: The characteristics and natural history of Japanese patients with nonalcoholic fatty liver diseases. Hepatol Res 33: 72-76, 2005. 
3. Ono M and Saibara T: Clinical features of nonalcoholic steatohepatitis in Japan: evidence from the literature. J Gastroenterol 41: 725-732, 2006

4. Harrison SA, Kadakia S, Lang KA and Schenker S: Nonalcoholic steatohepatits: what we know in the new millennium. Am J Gastroenterol 97: 2714-2724, 2002.

5. Ludwig J, Viggiano TR, McGill DB and Ott BJ: Nonalcoholic steatohepatitis Mayo Clinic experiences with a hitherto unnamed disease. Mayo Clin Proc 55: 434-438, 1980.

6. Powel EE, Cooksley WG, Hanson R, Searle J, Halliday JW and Powell JW: The natural history of steatohepatitis: a follow-up study of forty-two patients for up to 21 years. Hepatology 11 : 74-80, 1990 .

7. Yoshioka Y, Hashimoto E, Yatsuji S, Kaneda H, Taniai M, Tokushige K and Shiratori K: Nonalcoholic steatohepatitis: cirrhosis, hepatocellular carcinoma and burnt-out NASH. J Gastroenterol 39: 1215-1218, 2004.

8. Bugianesi E, Leone N, Vanni E, Marchesini G, Brunello F, Carucci P, Musso A, De Paolis P, Capussotti L, Salizzoni M and Rizzetto M: Expanding the natural history of NASH: from cryptogenic cirrhosis to hepatocellular carcinoma. Gastroenterology 123: $134-140,2002$.

9. Nakayama H, Otabe S, Ueno T, Hirota N, Yuan X, Fukutani T, Hashinaga $\mathrm{T}$, Wada $\mathrm{N}$ and Yamada $\mathrm{K}$ : Transgenic mice expressing nuclear sterol regulatory element-binding protein 1c in adipose tissue exhibit liver histology similar to nonalcoholic steatohepatitis. Metabolism 56: 470-475, 2007.

10. Bose M, Lambert JD, Ju J, Reuhl KR and Shapses SA: The major green tea polyphenol, (-)-epigallocatechin-3-gallate, inhibits obesity, metabolic syndrome, and fatty liver disease in high-fat-fed mice. J Nutr 138: 1677-1683, 2008.

11. Lee SM, Kim CW, Kim JK, Shin HJ and Baik JH: GCG-rich tea catechins are effective in lowering cholesterol and triglyceride concentrations in hyperlipidemic rats. Lipids 43: 419-429, 2008 .

12. Murase T, Nagasawa A, Suzuki J, Hase T and Tokimitsu I: Beneficial effects of tea catechins on diet-induced obesity: stimulation of lipid catabolism in the liver. Int J Obes 26 1459-1464, 2002.

13. Shimomura I, Hammer RE, Richardson JA, Ikemoto S, Bashmakov Y, Goldstein JL and Brown MS: Insulin resistance and diabetes mellitus in transgenic mice expressing nuclear SREBP-1c in adipose tissue: model for congenital generalized lipodystrophy. Genes Dev 12: 3182-3194, 1998

14. Matteoni CA, Younossi ZM, Gramlich T, Boparai N, Liu YC and McCullough AJ: Nonalcoholic fatty liver disease: a spectrum of clinical and pathological severity. Gastroenterology 116: 1413-1419, 1999.

15. Kleiner DE, Brunt EM, Van Natta M, Behling C, Contos MJ, Cummings OW, Ferrell LD, Liu YC, Torbenson MS Unalp-Arida A, Yeh M, McCullough AJ and Sanyal AJ: Nonalcoholic Steatohepatitis Clinical Research Network. Design and validation of a histological scoring system for nonalcoholic fatty liver disease. Hepatology 41: 1313-1321, 2005.

16. Korenblat KM, Fabbrini E, Mohammed BS and Klein A: Liver, muscle, and adipose tissue insulin action is directly related to intrahepatic triglyceride content in obese subjects. Gastroenterology 134: 1369-1375, 2008
17. Sanyal AJ: Mechanisms of disease: pathogenesis of nonalcoholic fatty liver disease. Nat Clin Pra Gastroenterol Hepatol 2: 46-53, 2005.

18. Surh YJ: Cancer chemoprevention with dietary phytochemicals. Nat Rev Cancer 3: 768-780, 2003.

19. Sakata R, Ueno T, Nakamura T, Sakamoto M, Torimura T and Sata M: Green tea polyphenol epigallocatechin-3-gallate inhibits platelet-derived growth factor-induced proliferation of human hepatic stellate cell line LI90. J Hepatol 40: 52-59, 2004.

20. Chen A, Zhang L, Xu J and Tang J: The antioxidant (-)-epigallocatechin3-gallate inhibits activated hepatic stellate cell growth and suppresses acetaldehyde-induced gene expression. Biochem J 368: 695-704, 2002.

21. Zhen M, Wang Q, Huang X, Cao L, Chen X, Sun K, Liu YJ, Li W and Zhang LJ: Green tea polyphenol epigallocatechin-3gallate inhibits oxidative damage and preventive effects on carbon tetrachloride-induced hepatic fibrosis. J Nutr Biochem 18: 795-805, 2007.

22. Yumei F, Zhou Y, Zheng S and Chen A: The antifibrogenic effect of (-)-epigallocatechin gallate results from the induction of de novo synthesis of glutathione in passaged rat hepatic stellate cells. Lab Invest 86: 697-709, 2006.

23. Fu Y, Zheng S, Lu SC and Chen A: Epigallocatechin-3-gallate inhibits growth of activated hepatic stellate cells by enhancing the capacity of glutathione synthesis. Mol Pharmacol 73: 1465-1473, 2008.

24. Csala M, Margitti E, Senesi S, Gamberucci A, Banhegyi G, Mandl J, et al: Inhibition of hepatic glucose 6-phosphatase system by the green tea flavanol epigallocatechin gallate. FEBS Lett 581: 1693-1698, 2007.

25. Collins QF, Liu H, Pi J, Liu Z, Quon MJ and Cao W: Epigallocatechin-3-gallate (EGCG), a green tea polyphenol, suppresses hepatic gluconeogenesis through 5'-AMP-activated protein kinase. J Biol Chem 282: 30143-30149, 2007.

26. Igarashi K, Honma K, Yoshinari O, Nanjo F and Hara Y: Effects of dietary catechins on glucose tolerance, blood pressure and oxidative status in Goto-Kakizaki rats. J Nutr Sci Vitaminol 53: 496-500, 2007.

27. Nagao T, Komine Y, Soga S, Meguro S, Hase T, Tanaka Y and Tokimitsu I: Ingestion of a tea rich in catechins leads to a reduction in body fat and malondialdehyde-modified LDL in men. Am J Clin Nutr 81: 122-129, 2005.

28. Angulo P: NAFLD, obesity, and bariatric surgery. Gastroenterology 130: $1848-1852,2006$

29. Bataller R, Sancho-Bru P, Gines P and Brenner DA: Liver fibrogenesis: a new role for the rennin-angiotensin system. Antioxid Redox Signal 7: 1346-1355, 2005.

30. Ding X, Saxena NK, Lin S, Xu A, Srinivasan S and Ananina FA: The roles of leptin and adiponectin: a novel paradigm in adipocytokine regulation of liver fibrosis and stellate cell biology. Am J Pathol 166: 1655-1669, 2005.

31. Oben JA, Roskams T, Yang S, Lin H, Sinelli N, Torbenson M, Smedh U, Moran TH, Li Z, Huang J, Thomas SA and Diehl AM: Hepatic fibrogenesis requires sympathetic neurotransmitters. Gut 53: 438-445, 2004 